\title{
Static Pull Testing of a New Type of Large Deformation Cable with Constant Resistance
}

\author{
Zhigang Tao, ${ }^{1,2,3}$ Shihui Pang, ${ }^{1,2}$ Yijun Zhou, ${ }^{4}$ Haijiang Zhang, ${ }^{1,2,3}$ and Yanyan Peng ${ }^{3}$ \\ ${ }^{1}$ State Key Laboratory for Geo-Mechanics \& Deep Underground Engineering, Beijing 100083, China \\ ${ }^{2}$ School of Mechanics and Civil Engineering, China University of Mining \& Technology, Beijing 100083, China \\ ${ }^{3}$ Center of Rock Mechanics and Geohazards, Shaoxing University, Shaoxing 312009, China \\ ${ }^{4}$ Architectural Engineering College, Beijing University of Technology, Beijing 100083, China \\ Correspondence should be addressed to Zhigang Tao; taozhigang@263.net
}

Received 1 October 2016; Revised 20 January 2017; Accepted 7 February 2017; Published 16 March 2017

Academic Editor: Patrice Berthod

Copyright ( 2017 Zhigang Tao et al. This is an open access article distributed under the Creative Commons Attribution License, which permits unrestricted use, distribution, and reproduction in any medium, provided the original work is properly cited.

\begin{abstract}
A new type of energy-absorbing cable, Constant-Resistance Large Deformation cable (CRLD cable) with three different specifications, has been recently developed and tested. An effective cable should occupy the ability of absorbing deformation energy from these geodisaster loads and additionally must be able to yield with the sliding mass movements and plastic deformation over large distances at high displacement rates. The new cable mainly consists of constant-resistance casing tube and frictional cone unit that transfers the load from the slope. When experiencing a static or dynamic load and especially the load exceeding the constant resistance force (CR-F, a static friction force derived from the movement of frictional cone unit in casing tube) of CRLD cable, the frictional cone unit will move in the casing tube along the axis and absorb deformation energy, accordingly. In order to assess the performance of three different specified cables in situ, a series of field static pull tests have been performed. The results showed that the first type of CRLD cable can yield $2000 \mathrm{~mm}$ displacement while acting $850 \mathrm{kN}$ static pull load, which is superior to that of other two types, analyzing based on the length of the displacement and the level of static pull load.
\end{abstract}

\section{Introduction}

Landslides that cause great damage and loss of life can be triggered by many elements, such as earthquakes, rainfall, engineering blasting, and slope excavating. Slope reinforcement of natural and excavated slopes is always a great concern of rock engineering. A lot of slope reinforcement devices have been developed to counteract landslides disasters such as rock bolts, prestressed tendon, soil nail, antislide pile, and boltwire mesh. These devices have positive effect on the stability and security of dangerous slope.

However, landslides disasters which occurred in the most unstable slopes belong to the large deformation of rock. Existing ideas of support and reinforcement for slope and underground engineering based on the conventional anchorage system cannot accommodate the large deformation damage of soil-rock mass, and many inharmonious phenomena have appeared in the process of underground engineering support, for example, sudden breaking of bolts, warping of steel frame, extraction of bolt, and repeated repairing of the supported roadway. So, an ideal reinforcement device should have the advantages of cable and the large deformation capacity of energy absorbing units. Rock bolts can be classified according to their properties such as strength bolt, ductile bolt, and energy absorbing bolts; these three categories of bolts are shown in Figure 1 [1].

(1) Strength bolt can provide a support load equal or close to the intrinsic strength of the bolt material.

(2) Ductile bolt is able to accommodate the large rock deformations, but the support load is very low.

(3) Energy absorbing bolt is characterized by its high load capacity and large deformation capacity.

In the early 1990s, Ortlepp pointed out that support devices used in deep mines should be able to carry high loads and also accommodate large deformations [2]. That means the effective support devices must be capable of 


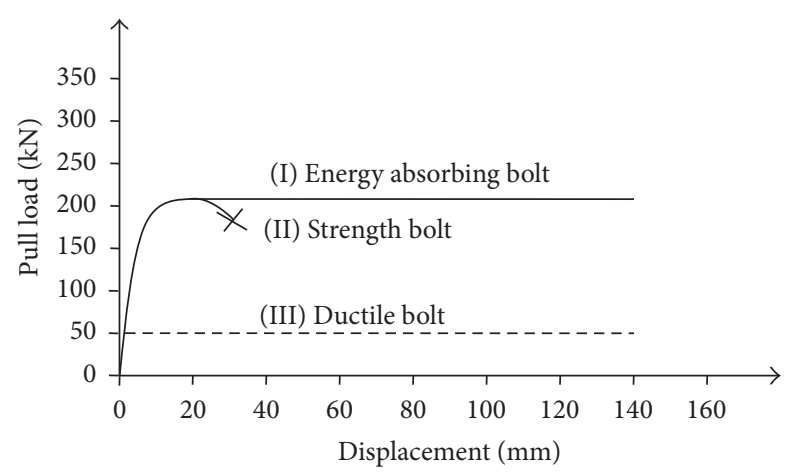

FIGURE 1: Concept of the ideal bolt and definitions of strong, ductile, and energy absorbing rock bolts (Stjern 1995). The curves for the rebar and split set are redrawn from Stjern [10].

absorbing a large amount of deformation energy prior to failure. However, the conventional reinforce and support devices cannot be provided with sufficient displacement to absorb surplus deformation energy before the failure.

A design philosophy for energy absorbing bolts was given by Mccreath and Kaiser [3], who put forth that the bolts must be allowed to yield and slide with the ground movements and also deform plastically over large distances at high displacement rates. The so-called cone bolt may be the first energy absorbing device designed to counteract rock burst problems and was invented in South Africa [4]. The cone bolt consists of a smooth steel bar with a flattened conical flaring forged onto one end [1]. The cone bolt was initially designed for use with cement grout. It was later adapted to resin grout, the so-called Modified Cone Bolt (MCB, for short) [5]. The MCB has a blade at the cone end to serve as a resin mixer. MCB is used in the dynamic rock support systems of many burst prone deep mines in Canada. Roofex is another energy absorbing bolt which was invented in Austria [6]. The Roofex bolts can yield $300 \mathrm{~mm}$ displacement while carrying $80 \mathrm{kN}$ pull load.

Additional energy absorbing bolts have appeared on the market in recent years, for example, the Garford bolt [7], yielding Secura bolt, and D bolt which is made of smooth steel bar with a number of integrated anchors spaced evenly or unevenly along its length [1], a new type of energy absorbing rock bolt with a $150 \mathrm{~mm}$ diameter curved circular disc $[8,9]$.

This paper describes a new type of energy absorbing cable with three different specifications and puts forward the results from a series of in situ static pull tests conducted on the CRLD cables in Nanfen open pit iron mine which is the largest monomer open pit iron mine in Asia with the objective of assessing their anchorage performance at the acclaimed yield load and displacement.

\section{A New Type of Large Deformation Cable}

2.1. Structure. The CRLD cable, patented by Professor HE Manchao and his teams, is actually a compound device consisting of following elements: nut, face plate, steel tendon, and energy absorber unit (energy absorber unit consists of the frictional cone unit, casing tube with its inner diameter slightly smaller than the diameter of the large-end diameter of the frictional cone unit, and the stop element as seen in Figures 2 and 3). Steel tendon is made of six or more smooth and high strength steel strands with $15.24 \mathrm{~mm}$ diameter. The small-end diameter of the frictional cone unit is designed a little smaller than the internal diameter of the casing tube in order to allow for the easy fitting of the cone unit into the casing tube. The large-end diameter of the cone unit is slightly larger than the inner diameter of the casing tube in order to generate the CR-F during the relative sliding between the frictional cone unit and casing tube $[11,12]$. In addition, $\mathrm{CR}-\mathrm{F}$ is designed under the elastic limit of the steel strands. Thus the $15.24 \mathrm{~mm}$ diameter steel strands only generate elastic deformation when external load is loaded on the CRLD cable.

The yielding action of the CRLD cable is provided through the energy absorber unit, and this unit is a $2000 \mathrm{~mm}$ long hollow cylinder with $133 \mathrm{~mm}$ external diameter, truncated on both ends. When the CRLD cable is subjected to a static or dynamic load and when the load exceeds the constant resistance force (we also call it frictional resistance force between the cone unit and the casing tube), the frictional cone unit will move in the casing tube along the axis and fix at $2000 \mathrm{~mm}$ from the cable's end as seen in Figure 2.

The casing tube is designed with three different inner diameters. The structural drawings of the above casing tube are shown in Figure 4. The geometrical parameters of casing tube and frictional cone unit are listed in Tables 1 and 2, respectively.

(a) CRLD-I indicates the casing tube with the $93 \mathrm{~mm}$ inner diameter and the $133 \mathrm{~mm}$ external diameter as well as the $20 \mathrm{~mm}$ wall thickness.

(b) CRLD-II indicates the casing tube with the $113 \mathrm{~mm}$ inner diameter and the $133 \mathrm{~mm}$ external diameter as well as the $10 \mathrm{~mm}$ wall thickness.

(c) CRLD-III indicates the casing tube with the $121 \mathrm{~mm}$ inner diameter and the $133 \mathrm{~mm}$ external diameter as well as the $6 \mathrm{~mm}$ wall thickness.

Having a larger diameter than the constant resistance tube, the cone unit's strength must be over the tube to avoid creep. The frictional movement of the cone unit along the tube is stopped by the stop element and the baffle at the two sides of energy absorbing unit. Because of environmental complexity in the borehole, a kind of special filling material is introduced against corrosion of energy absorbing units. The diameter of cone unit can be adjusted to improve the frictional force between the tube and the cone unit until a designed yield load is reached (e.g., $850 \mathrm{kN}$ ). When the pull load attains the yield load, the tube starts deforming because the materials strength of tube is inferior to that of the cone unit. The cone unit sliding through the tube is controlled by the frictional resistance.

2.2. Mechanical Analysis. The mechanical model between the frictional cone unit and the casing tube is indicated in Figure 5(a). As we have known, the diameters difference between top and bottom of the frictional cone unit is very 
TABLE 1: Geometrical parameter of constant casing tube.

\begin{tabular}{|c|c|c|c|c|c|}
\hline \multirow{2}{*}{ Specification } & \multicolumn{3}{|c|}{ Geometrical parameter $(\mathrm{mm})$} & \multirow{2}{*}{ Wall thickness (mm) } & \multirow{2}{*}{ Material properties } \\
\hline & External diameter/D & Inner diameter $/ A$ & Length/L & & \\
\hline CRLD-I & 133 & 93 & 2000 & 20 & 20\# steel \\
\hline CRLD-II & 133 & 113 & 2000 & 10 & 20\# steel \\
\hline CRLD-III & 133 & 121 & 2000 & 6 & 20\# steel \\
\hline
\end{tabular}

Note. $20 \#$ steel: the carbon content of this kind of steel is $0.2 \%$, the tensile strength is $253-500 \mathrm{MPa}$, and the elongation is $24 \%$. The strength of $20 \#$ steel is lower than $45 \#$ steel, but the toughness and plasticity are better.

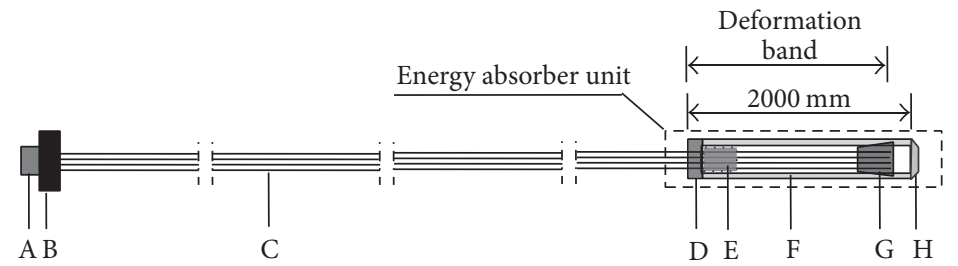

FIGURE 2: Components of a CRLD cable. A-nut; B-face plate; C-steel tendon, composed of 6 steel strands with 15.24 mm diameter; D-baffle; E-fill material; F-casing tubes; G-frictional cone unit; H-stop element (133 mm diameter).

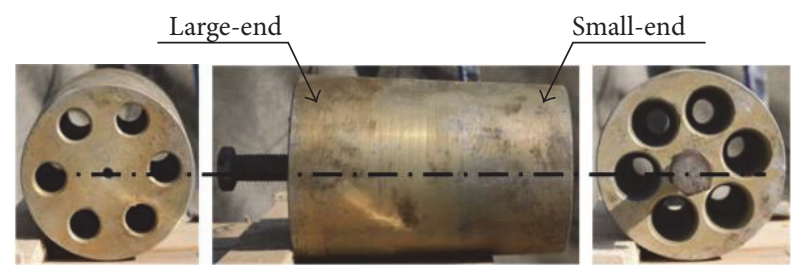

FIGURE 3: Structure of frictional cone unit.

small; therefore it can be simplified as a cylinder and is shown in Figure 5(b).

According to Hook's law and the limit equilibrium principle as follows:

$$
\begin{aligned}
P & =2 N \tan \phi, \\
\varepsilon & =\frac{\sigma}{E},
\end{aligned}
$$

where $P=2 N \tan \phi$ comes from the constitutive equation of tube material, $\phi$ indicated internal friction angle, and $N$ was normal pressure.

Microstrain $\varepsilon$ can be calculated by the following functions:

$$
\varepsilon=\frac{P \cdot c \tan \phi}{2 E S}
$$

where $c$ indicated cohesion of casing tubes materials and $S$ was cross-sectional area of simplified frictional cone unit.

Microstrain $\varepsilon$ indicates the frictional deformation of cone unit during the movement in casing tube. Before the design, diameter of bottom surface for cone unit can be calculated roughly to provide the basic parameters for product manufacture. However, there is quite a difference between theory and reality due to structure deformation of tube and the tests environments. The result shows that the theoretical calculation is not in good agreement with the test results and the test results are 2 orders of magnitude higher than theoretical arithmetic.

2.3. Energy Absorbing Capacity. There are two kinds of energies, one is resistance energy to deformation (expressed as $E_{R}$ ), and another one is absorbing energy to deformation (expressed as $E_{A}$ ). When the cable subjected to the static load which is less than the CR-F, the frictional cone units halt at the end of tube (Figure 6(a)). However, when the cable is subjected to a static or dynamic load and when the load exceeds the CR-F of CRLD cable, the frictional cone unit will move in the casing tube along the axis. The first stage belongs to the material deformation that depends on resistant load. The second stage belongs to the structural deformation that depends on absorbing deformation energy arisen from the static or dynamic load (expressed as $P$ ).

The total energy of CRLD cable can be expressed as follows:

$$
\Delta E=E_{R}+E_{A}
$$

where $E_{R}$ is resistance energy to deformation and $E_{A}$ is absorbing energy to deformation.

According to the energy absorbing curves shown in Figure 6, $E_{R}$ and $E_{A}$ can be calculated as follows:

$$
\begin{array}{ll}
E_{R}=\int_{0}^{U_{0}} P_{1}(U) d U & 0 \leq U \leq U_{0}, \\
E_{A}=\int_{U_{0}}^{U_{c}} P_{2}(U) d U & U_{0} \leq U \leq U_{c} .
\end{array}
$$

After simplification, (4) can be expressed as follows:

$$
\begin{aligned}
& E_{R}=\frac{1}{2} k U_{0}^{2}=\frac{1}{2} P_{0} U_{0} \quad 0 \leq U \leq U_{0}, \\
& E_{A}=P_{0} \Delta U=P_{0}\left(U_{c}-U_{0}\right) \quad U_{0} \leq U \leq U_{c} .
\end{aligned}
$$


TABLE 2: Geometrical parameter of frictional cone unit.

\begin{tabular}{|c|c|c|c|c|}
\hline \multirow{2}{*}{ Specifications } & \multicolumn{3}{|c|}{ Size of frictional cone unit } & \multirow{2}{*}{ Material properties } \\
\hline & Large-end diameter (mm) & Small-end diameter (mm) & Height (mm) & \\
\hline \multirow{6}{*}{ CRLD-I } & 96.0 & 93.0 & 150 & 45\# steel \\
\hline & 93.1 & 90.1 & 150 & $45 \#$ steel \\
\hline & 93.2 & 90.2 & 150 & 45\# steel \\
\hline & 93.1 & 90.0 & 150 & 45\# steel \\
\hline & 93.1 & 91.0 & 150 & 45\# steel \\
\hline & 93.1 & 88.0 & 150 & 45\# steel \\
\hline \multirow{4}{*}{ CRLD-II } & 115.0 & 110.0 & 150 & 45\# steel \\
\hline & 115.0 & 108.0 & 150 & 45\# steel \\
\hline & 121.0 & 111.0 & 150 & 45\# steel \\
\hline & 123.0 & 110.0 & 150 & 45\# steel \\
\hline \multirow{2}{*}{ CRLD-III } & 125.0 & 118.0 & 150 & 45\# steel \\
\hline & 125.0 & 117.0 & 150 & 45\# steel \\
\hline
\end{tabular}

Note. $45 \#$ steel: the carbon content of this kind of steel is $0.4 \%$, the tensile strength is more than $600 \mathrm{MPa}$, and the elongation is $16 \%$.

The strength of $45 \#$ steel is higher than $20 \#$ steel, but the toughness and plasticity are poor.

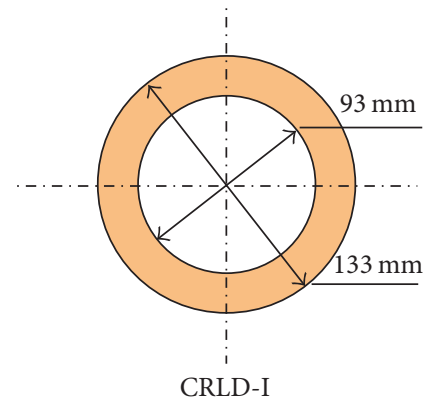

(a)

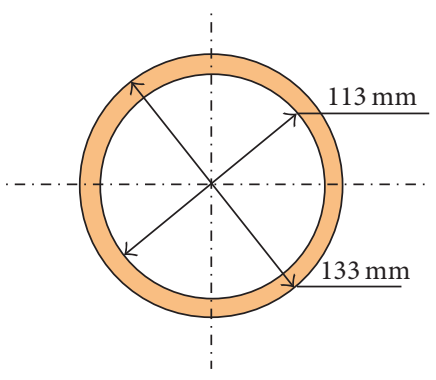

(b)

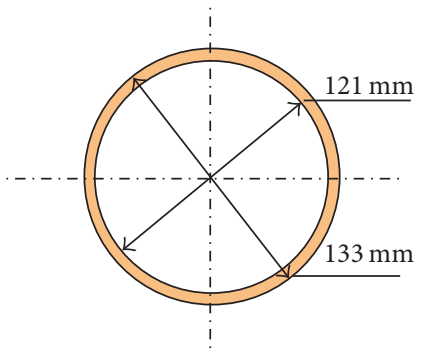

(c)

FIGURE 4: Section map of casing tube with three different inner diameters.

According to (3) and (5), total energy of CRLD cable can be expressed as follows:

$$
\Delta E=\frac{1}{2} P_{0}\left(2 U_{c}-U_{0}\right)
$$

where $U_{c}$ and $U_{0}$ can be obtained by the static pull tests.

\section{Working Principle of New Cable}

The CRLD cable consists of a frictional cone unit to steel sliding system, which moves on a constant resistance load level along the casing tube. The frictional cone unit and the casing tube are the core components of energy absorbing units. The sliding function generates friction between the fixed energy absorbing unit and the pulled through inner steel strand which absorbs the energy released from sliding mass movement. Even if the large deformations are beyond 2 meter (the maximum value of deformation), the CRLD cable is still able to deal with prevailing residual loads. This is because the CRLD cable also owns characters of traditional reinforcement device and will reach its ultimate load value, when reaching the deformation maximum value.

All energy absorbing devices counteract both landslides and rock burst that occur during engineering excavation proposed in the literature can be classified into two types in accordance with their energy absorbing mechanisms and working principles [13].

(1) Body of Rod Yieldable Bolts. This kind of bolt realizes energy absorbing function by the material yield strength and elongation (classified as material deformation), for example, D bolt [1], S-shaped bolt, and new type of energy absorbing rock bolt with a $150 \mathrm{~mm}$ diameter curved circular disc [8, 9]. These bolts tolerate small deformations prior to failure, making it a strong but stiff rock bolt.

(2) Structural Units Movable Bolts. This kind of bolt realizes energy absorbing function by the special physical construction (classified as structural deformation), for example, cone bolt [4] and Roofex bolt [6]. These bolts can accommodate large rock deformations. When subjected to a static or dynamic load, and when the load exceeds the threshold value of bolts, the "energy absorber" unit will move in the casing tube along the axis.

Figure 7 shows the working principle of the CRLD cable at three different stages of landslides, including the states before, during, and after the landslide disaster. 


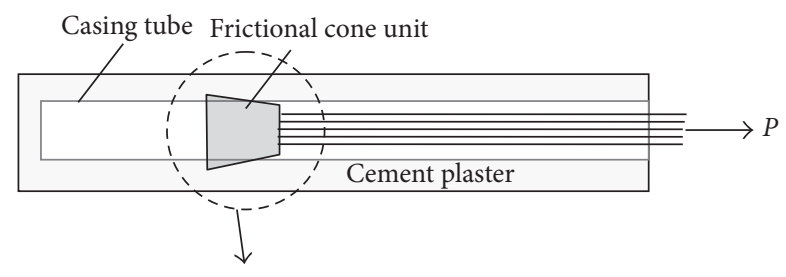

(a)

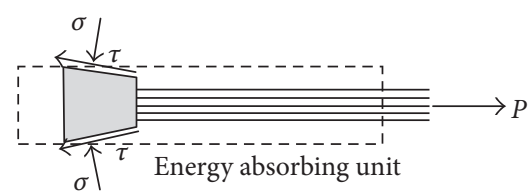

(b)

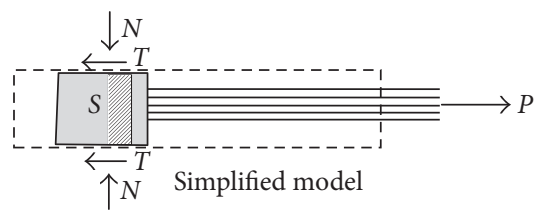

(c)

FIGURE 5: Mechanical model of cone unit. (a) Structural model of energy absorbing unit; (b) mechanical analysis between the frictional cone unit and the casing tube; (c) simplified model came from (b).

The yellow color in Figure 7 indicates the sliding mass, blue color indicates the steel strand, and red color indicates the energy absorbing unit and its deformation band. The monitoring equipment installed at the external end of the cable is invented by State Key Laboratory for Geo-mechanics and Deep Underground Engineering $[14,15]$ to collect and transmit the mechanical information on the sliding surface. The internal end of cable is fixed by the cement plaster in the borehole.

(1) The first stage shown is the state before the landslide disasters and after installation prior to any loading. At present, sliding mass is stable, and the rock deformation is very small. The anchored force is supplied by anchor cable itself for material deformation.

(2) The second stage shows energy absorbing phase when the cable is pulled through the energy absorber's grip while the remainder of the steel strand moves freely inside the casing tubes that protects it from being in contact with the cement plaster and provides enough friction force between the cone unit and the tubes.

(3) The third stage shows the CRLD cable after the maximum deformation has been achieved, which indicates that the energy absorber unit remains anchored in the same position in the borehole.

\section{Static Pull Tests}

4.1. Testing System. The field static pull tests were performed at Nanfen open pit iron mine, which is the largest monomer open pit iron mine in Asia. The test was performed using of Orient Victory Machine (OVM, for short) brand of jack equipped with a high voltage electric oil pump (product model is YBZ $2 * 2-50$, and 50 indicates the $50 \mathrm{MPa}$ rated oil pressure). The pull load applied was $35 \mathrm{~mm} / \mathrm{min}$, and the ultimate pull load is $1250 \mathrm{kN}$. The mechanical sensor was connected to a computer which recorded the loads in real time. Figure 8 shows the assembling sketch map of OVM through jack and test piece before the static pull tests.

4.2. Important Parameters. According to the test purpose and the test content, the following pull test parameters were identified as important and methods for their determination were established.

(1) Pull Load. The pull load applied on the cable was measured by the pressure sensor and OVM through jack during the testing period and recorded on the computer.

(2) Frictional Cone Unit Displacement. The displacement induced on the cone unit was monitored by autodisplacement meter with the $2500 \mathrm{~mm}$ measure range fixed on the end of casing tube. The displacement data was recorded on the data collection equipment, which also allowed generation of real time plots of time-displacement performance of the cone unit, and the collecting frequency is around 30 data per minute.

(3) Radial Deformation of Casing Tube. The radial deformation induced on the frictional force between the cone unit and the casting tube was measured by the artificial survey using the micrometer.

(4) Oil Pressure of High Voltage Electric Oil Pump. The oil pressure was measured by the pressure gauge within the high voltage electric oil pump during the testing period and recorded by human timely. There are two pressure gauges; one displays the oil pressure of loading and another one displays the oil pressure of unloading. Usually, the loading oil pressure is our concerned parameter in the process of testing, and the relationship between the oil pressure and the pull load measured by pressure sensor can be determined.

(5) Testing Temperature. Testing temperature was measured by the thermometer in order to check whether the temperature is influential to the results of testing.

4.3. Results of Tests. The design of test calls for the constant resistance tube to be fixed without rolling. Static pull tests were performed to optimize the structural parameters (e.g., number of steel strand, diameter of steel strand), the geometric parameters (e.g., diameter of cone unit, length of tube), and the technical parameters (e.g., CR-F, maximum deformation) of cable.

According to the diameters of constant resistance casing tubes and frictional cone unit, samples are classified as three groups, which are named CRLD-I, CRLD-II, and CRLD-III. Figure 4 and Tables 1 and 2 show three samples used in the pull tests. There are 16 groups of field examples which were performed in Nanfen open pit iron mine. 


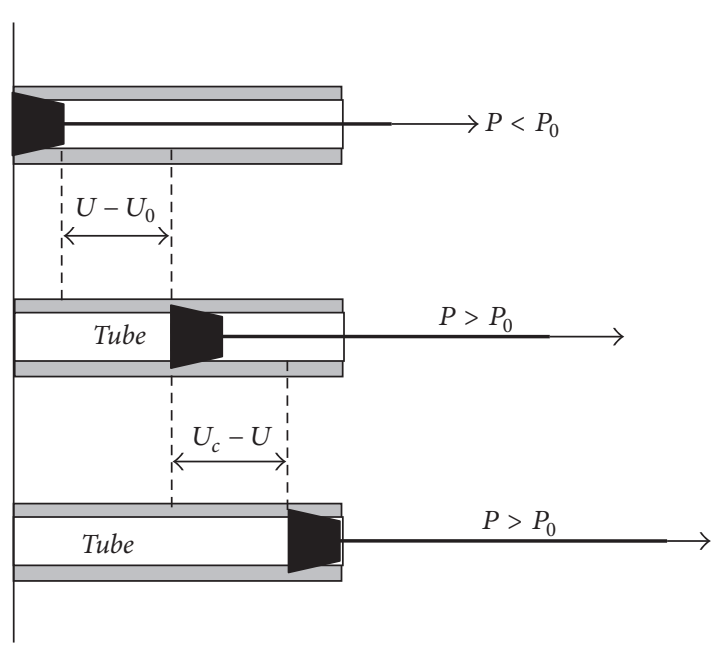

(a)
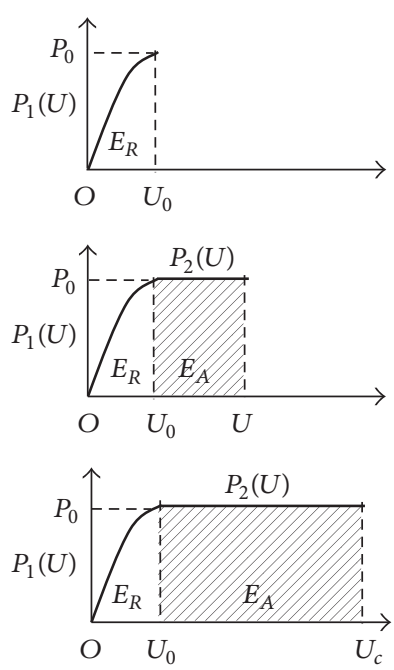

(b)
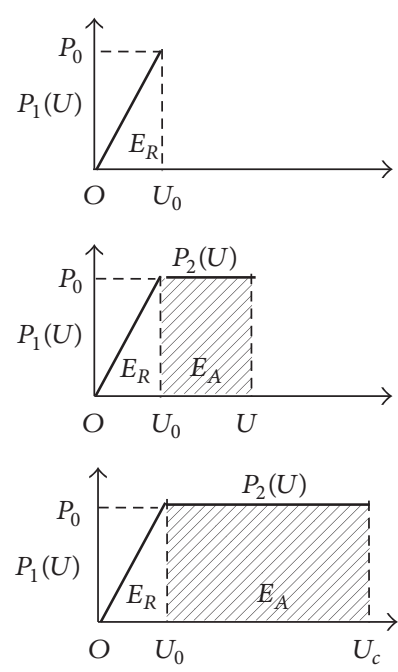

(c)

FIGURE 6: The process of energy absorbing and its corresponding curves. (a) Sketch map in the process of energy absorbing with three different stages. (b) Energy absorbing curves, obtained by in situ static pull tests. (c) Simplified curves of energy absorbing.

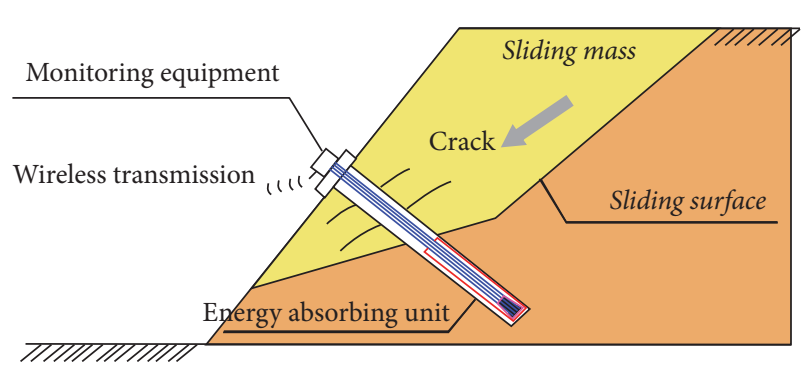

(a)

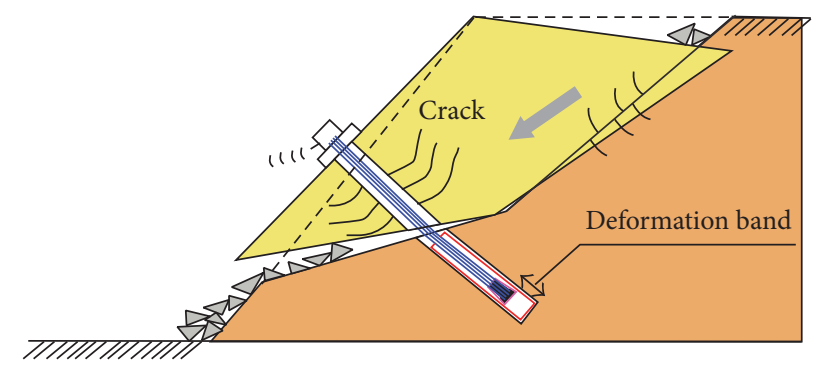

(b)

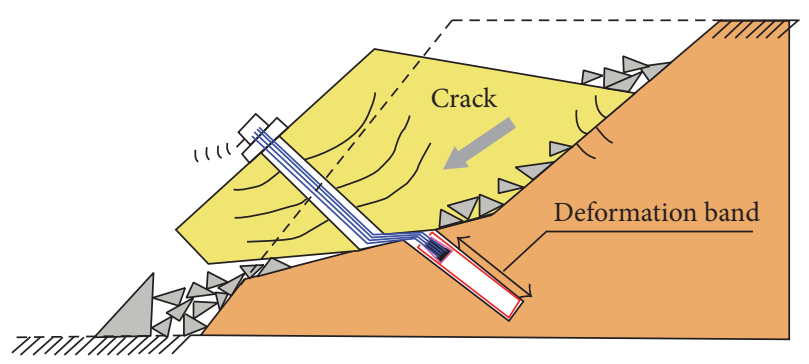

(c)

FIGURE 7: Yielding stages of a CRLD cable. (a) Before the landslide l; (b) landslide occurrence; (c) after the landslide.

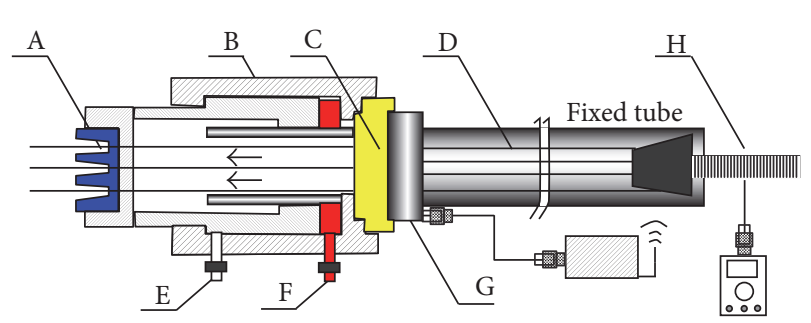

FIGURE 8: Components of a CRLD cable. A: anchorage; B: OVM through jack; C: displacement limit plate; D: test piece; E: oil outlet; F: oil supply hole; G: pressure sensor; H: autodisplacement meter.

The results of 16 groups of examples indicate that the casting tubes with $113 \mathrm{~mm}$ and $121 \mathrm{~mm}$ inner diameter begin to radially deform and axially bend due to the structural imperfection in the process of loading (Figure 9). The maximum radial deformation is around $12 \mathrm{~mm}$, and the maximum axial bending is around 12 degree. These deformation characteristics indicate that CRLD cables with CRLD-II and CRLDII style cannot satisfy the optimal energy absorbing capability in practice. In additional, because of the large frictional force due to the diameter of cone units being much larger than the ones of casing tubes, there are many striated frictional traces in the tube inwall, and the tearing phenomenon of steel with the fragment (around $12 \mathrm{~mm}$ height) in the casting tube inwall appeared partly in the process of pull tests (Figure 10). The fragment seriously has hindered the movement of frictional cone unit in the casting tube; tests 1,2,3, and 4 are the best examples. Thus, the key that whether the tests are successful or not lies in the structural parameter and the geometric parameter of frictional cone unit.

Figure 11 shows the CR-F and displacement plots developed from the field pull test results. All of the cables indicate the obvious constant resistance characteristics. Tests 1, 2, 3, 4, 

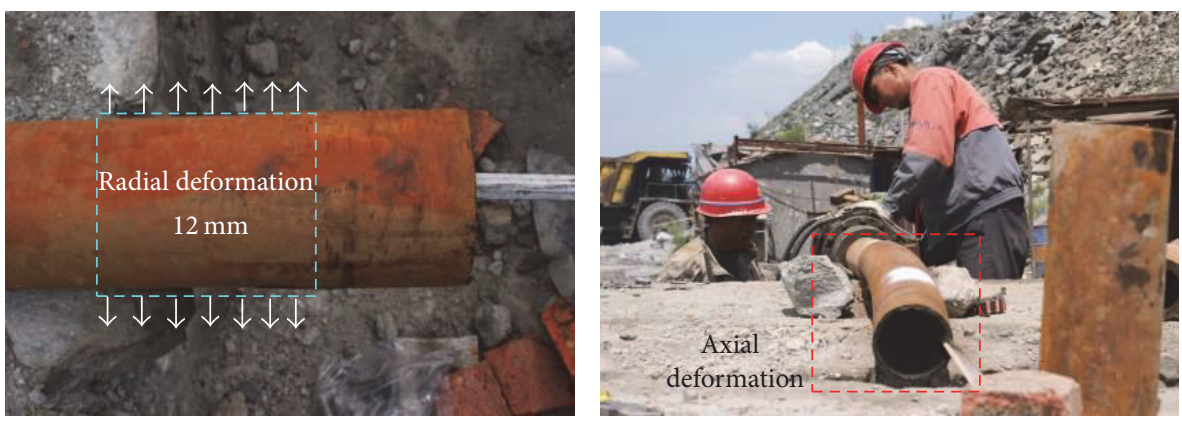

FIGURE 9: Axial and radial deformation of constant resistance casing.
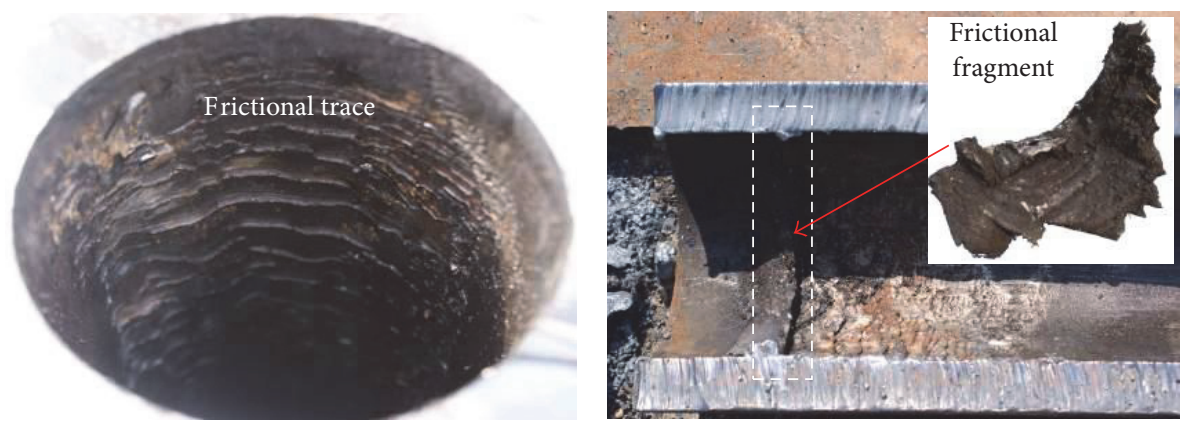

FIGURE 10: Friction trace in the constant resistance casing inwall.

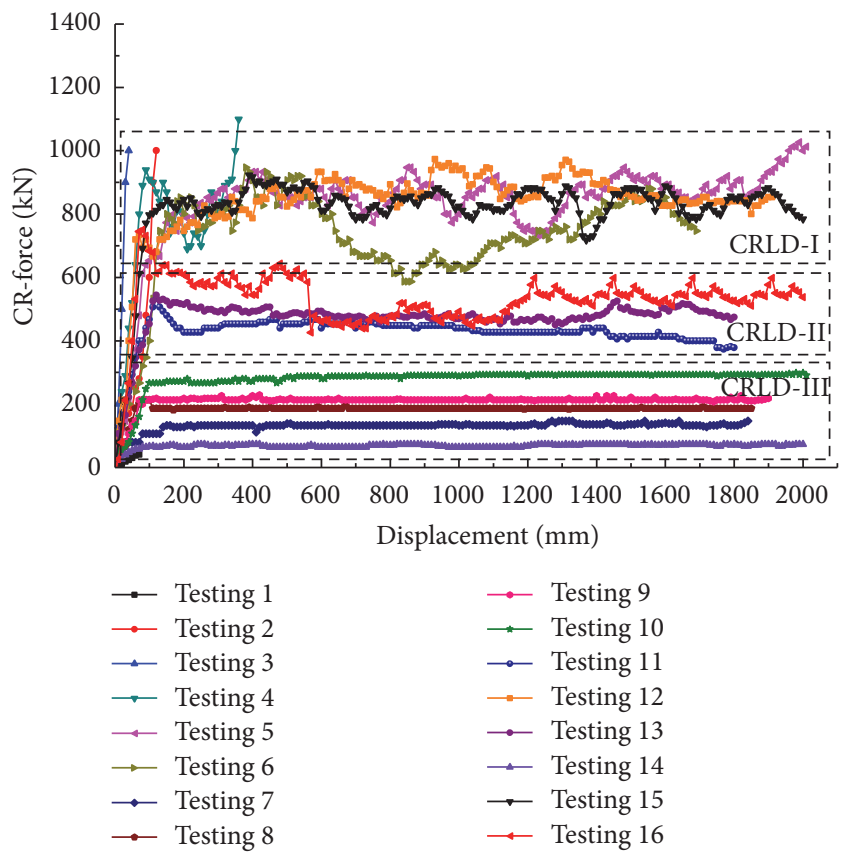

FIGURE 11: Static pull testing curve of constant resistance large deformation cable.

$5,6,7$, and 8 were performed on CRLD-I style cables. Tests 9, 10 , and 11 were performed on CRLD-II style cables. Tests 12, $13,14,15$, and 16 were performed on CRLD-III style cables. The graphs show that the new type of cable with CRLD-I style began to yield at load of approximately $700 \mathrm{kN}$ to $980 \mathrm{kN}$, and the CRLD cable with CRLD-II style began to yield at load of approximately $380 \mathrm{kN}$ to $650 \mathrm{kN}$, and the CRLD cable with CRLD-III style began to yield at load of approximately $40 \mathrm{kN}$ to $350 \mathrm{kN}$. These tests were stopped at $2000 \mathrm{~mm}$ of displacement.

The irregularities before reaching the yield load in the CRF and displacement plot for tests 1, 2, 3, and 4 with invalid results are caused by the cones having been locked in the casing tube, which is because the diameters of cone units are much larger than the ones of casing tubes and the inwall of casing tube has no lubricant. Test 1 was stopped at $70 \mathrm{~mm}$ of displacement, test 2 was stopped at $120 \mathrm{~mm}$ of displacement, test 3 was stopped at $40 \mathrm{~mm}$ of displacement, and test 4 was stopped at $360 \mathrm{~mm}$ of displacement.

In general, the overall steadiness of the energy absorbing behavior accords with the expected performance.

4.4. Energy Analysis. According to the energy absorbing equation (6), the absorbing energy and the resistance energy of CRLD cable can be obtained by the testing results and testing curves (around 12 groups of examples results can be accepted and trusted). The calculation results of energy were shown in Table 3.

In order to explore the relationship between the CR-F and the energy absorbing capability, CR-F and energy are obtained from 12 groups of testing, as shown in Table 3. $x$ axis of plots indicates the CR-F, expressed as $P_{0} \cdot y$-axis of plots indicates the total energy, expressed as $E$. The plot is shown in Figure 12.

There is a significant linear relationship between the CR-F and the total energy $\left(R^{2}=0.9908, p<0.05\right)$, and the 
TABLE 3: Calculation results of energy of CRLD cable.

\begin{tabular}{|c|c|c|c|c|c|c|c|}
\hline \multirow[b]{2}{*}{ Number } & \multicolumn{3}{|c|}{ Basic parameter } & \multirow[b]{2}{*}{$\begin{array}{c}\text { Resistance } \\
E_{R} / \mathrm{J}\end{array}$} & \multirow[b]{2}{*}{$\begin{array}{c}\text { Absorbing } \\
E_{A} / \mathrm{J}\end{array}$} & \multirow[b]{2}{*}{$\begin{array}{l}\text { Total } \\
\Delta E / \mathrm{J}\end{array}$} & \multirow[b]{2}{*}{ Specification } \\
\hline & $\begin{array}{l}\text { CR-F } \\
P_{0} / \mathrm{kN} \\
\end{array}$ & $\begin{array}{c}\text { CR-displacement } \\
U_{0} / \mathrm{mm} \\
\end{array}$ & $\begin{array}{c}\text { Max-displacement } \\
U_{c} / \mathrm{mm}\end{array}$ & & & & \\
\hline Test 5 & 850 & 250 & 2000 & 106.25 & 1487.50 & 1593.75 & CRLD-I \\
\hline Test 6 & 800 & 200 & 2000 & 80.00 & 1440.00 & 1520.00 & CRLD-I \\
\hline Test 7 & 140 & 200 & 2000 & 14.00 & 252.00 & 266.00 & CLRD-III \\
\hline Test 8 & 190 & 100 & 2000 & 9.50 & 361.00 & 370.50 & CLRD-III \\
\hline Test 9 & 220 & 125 & 2000 & 13.75 & 412.50 & 426.25 & CLRD-III \\
\hline Test 10 & 190 & 125 & 2000 & 11.88 & 356.30 & 368.13 & CLRD-III \\
\hline Test 11 & 450 & 100 & 2000 & 22.50 & 855.00 & 877.50 & CRLD-II \\
\hline Test 12 & 900 & 150 & 2000 & 67.50 & 1665.00 & 1732.50 & CRLD-I \\
\hline Test 13 & 500 & 150 & 2000 & 37.50 & 925.00 & 962.50 & CRLD-II \\
\hline Test 14 & 70 & 180 & 2000 & 6.30 & 127.40 & 133.70 & CRLD-III \\
\hline Test 15 & 850 & 200 & 2000 & 85.00 & 1530.00 & 1615.00 & CRLD-I \\
\hline Test 16 & 600 & 100 & 2000 & 30.00 & 1140.00 & 1170.00 & CRLD-I \\
\hline
\end{tabular}

Note. The displacement when CRLD cable achieves constant resistance moment. (CR-displacement).

The displacement when CRLD cable achieves maximum constant resistance moment (max-displacement).

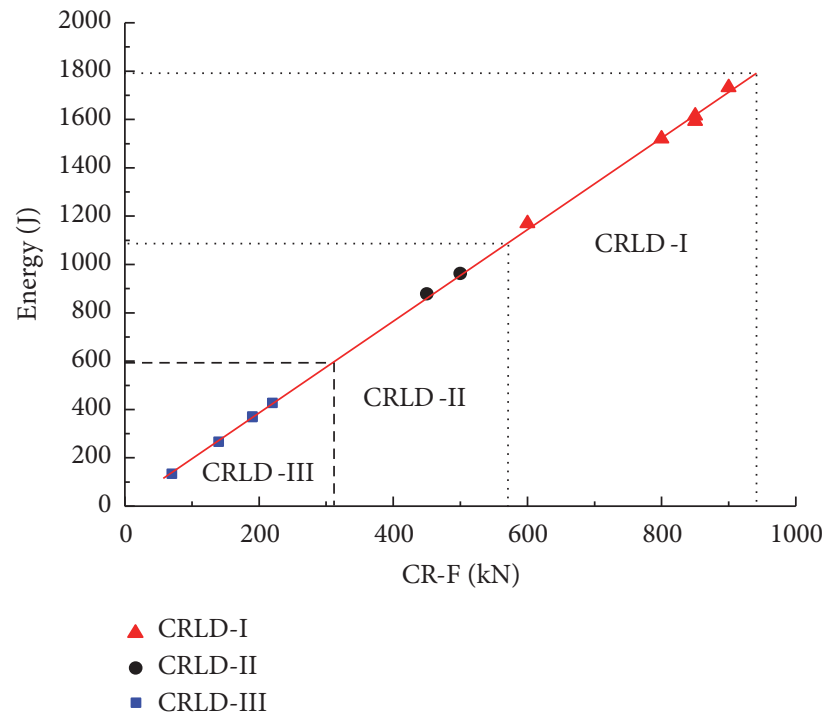

FIGURE 12: Relationship curves between the CR-force and the total energy.

classification characteristics of energy are very obvious. Energy interval of CRLD cable with CRLD-III, CRLD-II, and CRLD-I style, range from 0 to $600 \mathrm{~J}, 600$ to $1100 \mathrm{~J}$, and 1100 to $1800 \mathrm{~J}$, respectively.

\section{Discussion of the Test Results}

The field tests results performed in Nanfen open pit iron mine showed performance characteristics of the $850 \mathrm{kN}$ yield load and $2000 \mathrm{~mm}$ displacement CRLD cable with CRLD-I style remaining close to design specifications. An important objective of the test was to find out whether the energy absorbing mechanism of the CRLD cable could assure the cable security and avoid tensile failure. The results of the $850 \mathrm{kN}$ yield and $2000 \mathrm{~mm}$ displacement cable pull tests show that this type of cables performed in slope as good as they expected. However, the CR-F and displacement plots of these kinds of cables (Figure 11) show reasonably uniform performance with less deviation from the design values, caused by the structural defect of casting tube inwall. The CRLD cable with three kinds of specifications has different energy absorbing characteristics.

(1) CRLD-I Style. The results show that CRLD cable with CRLD-I style began to yield at load of approximately $850 \mathrm{kN}$, and the minimum $\mathrm{CR}-\mathrm{F}$ is $620 \mathrm{kN}$ and maximum $\mathrm{CR}-\mathrm{F}$ is $940 \mathrm{kN}$. The average displacement of cone unit is around $1900 \mathrm{~mm}$, and the maximum displacement is $2200 \mathrm{~mm}$ and the minimum displacement is $1800 \mathrm{~mm}$. Because of the structural defect of the casting tube inwall and the excessive thick tube wall, the fluctuant amplitude of CR-F and displacement curves is bigger. However, all curves are fluctuating on $850 \mathrm{kN}$, and the new type of cable complies with the design requirements.

(2) CRLD-II Style. The results show that CRLD cable with CRLD-II style began to yield at load of approximately $470 \mathrm{kN}$, and the minimum CR-F is $400 \mathrm{kN}$ and maximum CR-F is $570 \mathrm{kN}$. The average displacement of cone unit is around $1900 \mathrm{~mm}$, and the maximum displacement is $2100 \mathrm{~mm}$ and the minimum displacement is $1700 \mathrm{~mm}$. Because of the lower CR-F, this kind of cable does not accord with a design to provide enough strength and yield load. However, these tests curves of CR-F have the relative straight displacements due to the lower frictional force between the cone unit and the casing tube.

(3) CRLD-III Style. The results show that CRLD cable with CRLD-III3 style began to yield at load of approximately $150 \mathrm{kN}$, and the minimum CR-F is $80 \mathrm{kN}$ and maximum CR$\mathrm{F}$ is $220 \mathrm{kN}$. The average displacement of cone unit is around $1900 \mathrm{~mm}$, and the maximum displacement is $2000 \mathrm{~mm}$ and 
the minimum displacement is $1800 \mathrm{~mm}$. Because of the lower CR-F and the large radial/axial deformation of tube, this kind of cable does not accord with a design to provide enough strength and yield load. However, these tests curves of CR$\mathrm{F}$ have the relative straight displacement as well as the ones with CRLD-III style.

It should be noted that all the interpretations and opinions presented in this paper are based on the monitored and measured data. Further verifications of the findings would require additional efforts, such as field pull tests in the borehole.

\section{Conclusions}

The static pull test showed performance characteristics of the $850 \mathrm{kN}$ yield load and $2000 \mathrm{~mm}$ displacement CRLD cables with CRLD-I style remaining close to their design specifications. However, it must be noted that the dynamic pull tests have not been performed. Further studies of the performance of these cables in actual excavating conditions, including under dynamic loading ones, are necessary for a more complete assessment of effectiveness of these cables. In order to further investigate the effect of dynamic tensile forces on CRLD cables, a high-Joule impact testing machine is being developed, which is capable of conducting tensile tests with maximum impact energy of $30000 \mathrm{~J}$.

State Key Laboratory for Geo-mechanics and Deep Underground Engineering is committed to creating a safer and more ergonomic working environment. The CRLD cable will come to secure the reinforcement of slope and will completely break the traditional reinforcement thinking for conventional anchorage cable.

\section{Conflicts of Interest}

The authors declare that there are no conflicts of interest regarding the publishing of this paper.

\section{Acknowledgments}

The research was supported by the funding of National Natural Science Foundation of China (nos. 41502323 and 41602308) and the Open Fund of Zhejiang Collaborative Innovation Center for Prevention and Control of Mountain Geologic Hazards (no. PCMGH2016Z02). Static pull tests and in situ application information presented in this paper were obtained during a contract project supported by Nanfen open pit iron mine. The authors would like to thank the managements of iron mining companies as well as the State Key Laboratory for Geo-mechanics and Deep Underground Engineering for their support and assistance in making theses research findings possible. The authors also express gratitude to other participants for their support.

\section{References}

[1] C. Chunlin Li, "A new energy-absorbing bolt for rock support in high stress rock masses," International Journal of Rock Mechanics and Mining Sciences, vol. 47, no. 3, pp. 396-404, 2010.
[2] W. D. Ortlepp, "Invited lecture: the design of support for the containment of rockburst damage in tunnels-an engineering approach," in Proceedings of the International Symposium on Rock Support, pp. 593-609, Sudbury, Canada, June 1992.

[3] D. R. Mccreath and P. K. Kaiser, "Current support practices in burst-prone ground, mining research directorate," in Canadian Rockburst Research Project (1990-95), Geomechanics Research Centre, Laurentian University, Sudbury, Canada, 1995.

[4] A. F. Jager, "Two new support units for the control of rockburst damage," in Rock Support in Mining and Underground Construction, P. K. Kaiser and D. R. Mccreath, Eds., pp. 621-631, Balkema, Rotterdam, The Netherlands, 1992.

[5] B. Simser, "Modified Cone Bolt Static and Dynamic Tests," Noranta Technology Centre Internal Report, Noranta Technology Centre, Quebec, Canada, 2002.

[6] U. Ozbay, "In-situ pull testing of a yieldable rock bolt, ROOFEX," in Controlling Seismic Hazard and Sustainable Development of Deep Mines, C. A. Tang, Ed., pp. 1081-1090, Rinton Press, Paramus, NJ, USA, 2009.

[7] R. Varden, R. Lachenicht, J. Player, A. Thompson, and E. Villaescusa, "Development and implementation of the Garford dynamic bolt at the Kanowna Belle Mine," in Proceedings of the 10th Underground Operators Conference, 19 pages, Launceston, Australia, April 2009.

[8] A. Ansell, "Laboratory testing of a new type of energy absorbing rock bolt," Tunnelling and Underground Space Technology, vol. 20, no. 4, pp. 291-300, 2005.

[9] A. Ansell, "Dynamic testing of steel for a new type of energy absorbing rock bolt," Journal of Constructional Steel Research, vol. 62, no. 5, pp. 501-512, 2006.

[10] G. Stjern, Practical performance of rock bolts [Ph.D. thesis], Universitetet I Trondheim, Trondheim, Norway, 1995.

[11] Z. G. Tao, H. J. Zhang, Y. F. Chen, and C. Jiang, "Support principles of NPR bolt/cable and control techniques of largedeformation disasters," International Journal of Mining Science and Technology, vol. 26, no. 6, pp. 967-973, 2016.

[12] M. C. He, W. L. Gong, J. Wang et al., "Development of a novel energy-absorbing bolt with extraordinarily large elongation and constant resistance," International Journal of Rock Mechanics \& Mining Sciences, vol. 67, pp. 29-42, 2014.

[13] C. J. Hou and Y. N. He, "Principle and application of rock bolts with extensible rod," Chinese Journal of Rock Mechanics and Engineering, vol. 16, no. 6, pp. 544-549, 1997.

[14] M. C. He, "Research on the double-block mechanics based on Newton force measurement," Chinese Journal of Rock Mechanics and Engineering, vol. 35, no. 11, pp. 2161-2173, 2016.

[15] Z.-G. Tao, H.-P. Li, G.-L. Sun, L.-J. Yin, and X.-L. Zhang, "Development of monitoring and early warning system for landslides based on constant resistance and large deformation anchor cable and its application," Rock and Soil Mechanics, vol. 36, no. 10, pp. 3032-3040, 2015. 

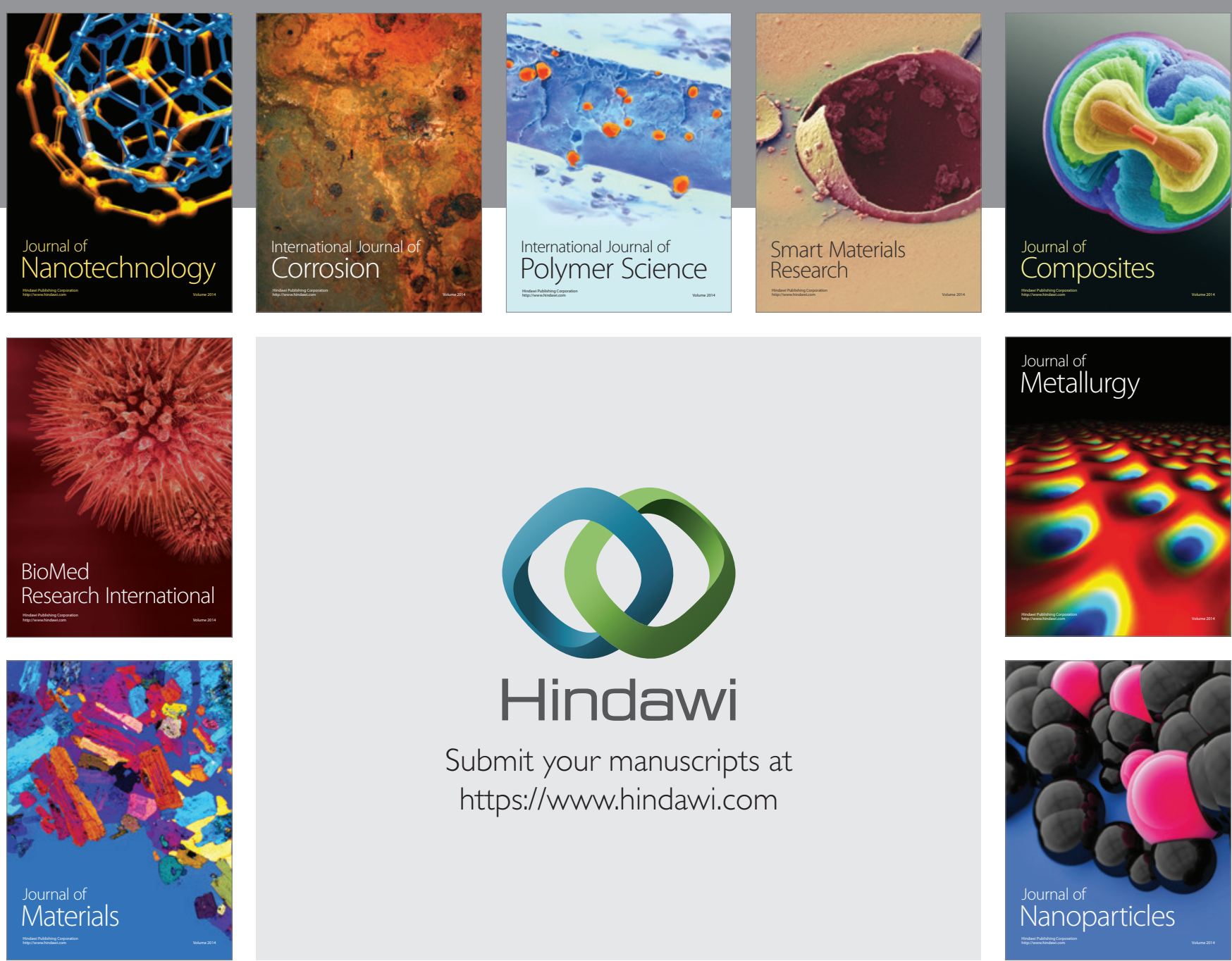

\section{Hindawi}

Submit your manuscripts at

https://www.hindawi.com

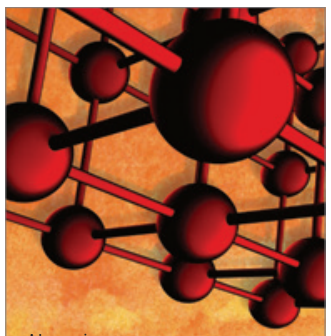

Materials Science and Engineering
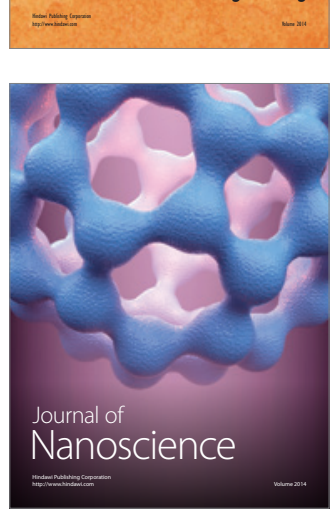
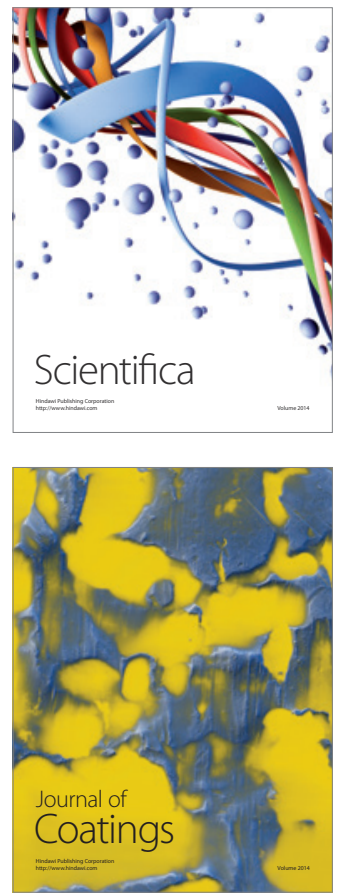
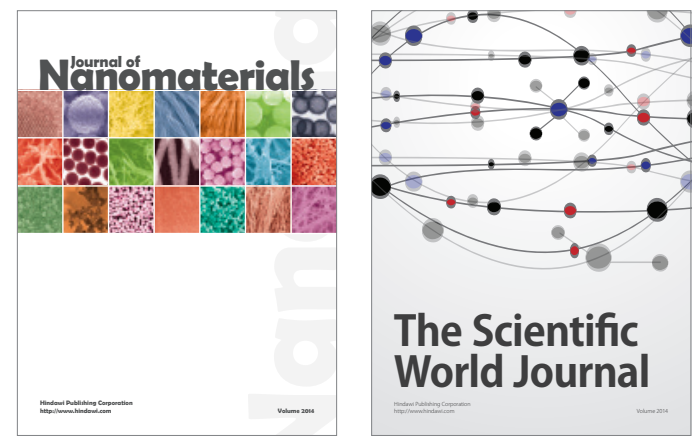

The Scientific World Journal
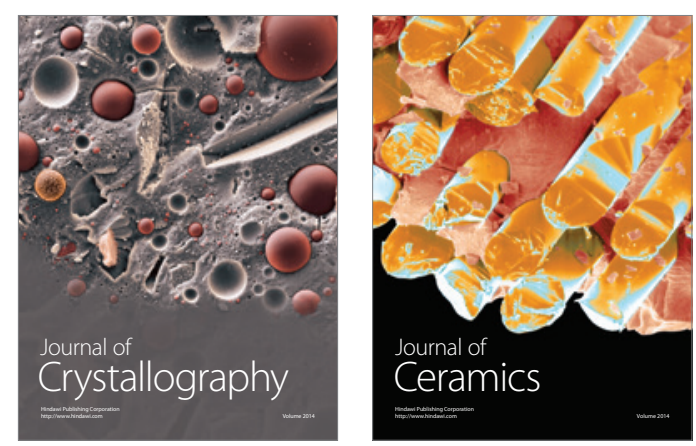
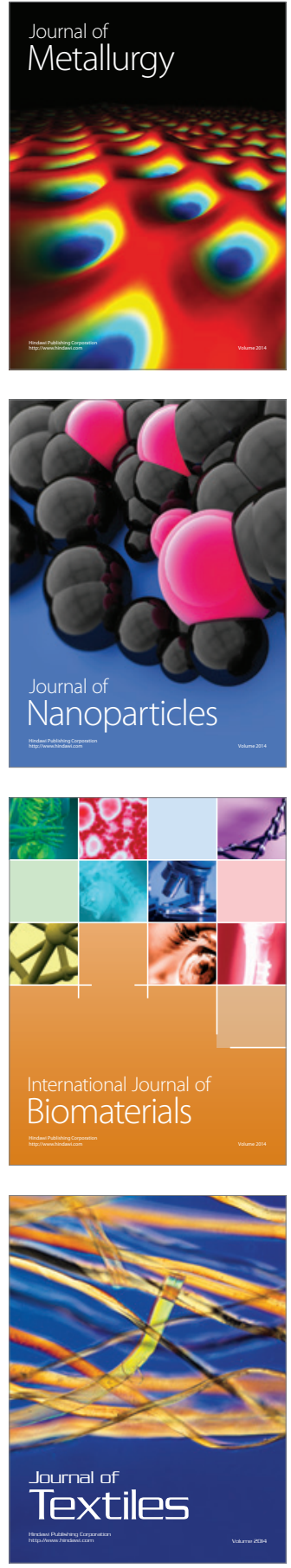